\title{
Home-based HIV counseling and testing: Client experiences and perceptions in Eastern Uganda
}

\author{
David Kyaddondo ${ }^{1 *}$, Rhoda K Wanyenze ${ }^{2}$, John Kinsman³ and Anita Hardon ${ }^{4}$
}

\begin{abstract}
Background: Though prevention and treatment depend on individuals knowing their HIV status, the uptake of testing remains low in Sub-Saharan Africa. One initiative to encourage HIV testing involves delivering services at home. However, doubts have been cast about the ability of Home-Based HIV Counseling and Testing (HBHCT) to adhere to ethical practices including consent, confidentiality, and access to HIV care post-test. This study explored client experiences in relation these ethical issues.

Methods: We conducted 395 individual interviews in Kumi district, Uganda, where teams providing HBHCT had visited 6-12 months prior to the interviews. Semi-structured questionnaires elicited information on clients' experiences, from initial community mobilization up to receipt of results and access to HIV services post-test.

Results: We found that 95\% of our respondents had ever tested (average for Uganda was 38\%). Among those who were approached by HBHCT providers, $98 \%$ were informed of their right to decline HIV testing. Most respondents were counseled individually, but $69 \%$ of the married/cohabiting were counseled as couples. The majority of respondents (94\%) were satisfied with the information given to them and the interaction with the HBHCT providers. Most respondents considered their own homes as more private than health facilities. Twelve respondents reported that they tested positive, 11 were referred for follow-up care, seven actually went for care, and only 5 knew their CD4 counts. All HIV infected individuals who were married or cohabiting had disclosed their status to their partners.

Conclusion: These findings show a very high uptake of HIV testing and satisfaction with HBHCT, a large proportion of married respondents tested as couples, and high disclosure rates. HBHCT can play a major role in expanding access to testing and overcoming disclosure challenges. However, access to HIV services post-test may require attention.
\end{abstract}

Keywords: Home-based HIV counseling and testing, Africa

\section{Background}

HIV testing and counseling is the gateway to prevention, care and treatment since these interventions depend on individuals seeking HIV testing and knowing their HIV status [1]. Additionally, studies have suggested that early initiation of HIV treatment may have important prevention benefits [2-4]. Despite the importance of HIV Counseling and Testing (HCT), its uptake remains low, particularly in developing countries. HIV testing in fact remains one of the greatest challenges to current HIV/AIDS policy [5,6]. Globally, over $60 \%$ of HIV-

\footnotetext{
* Correspondence: kyaddondo@hotmail.com

'Department of Social Work/Child Health and Development Centre,

Makerere University, Kampala, Uganda

Full list of author information is available at the end of the article
}

infected individuals remain unaware of their sero-status [7]. In Sub-Saharan Africa, it is estimated that $80 \%$ are unaware of their status and nearly $90 \%$ are unaware of their partner's status [8].

Global concern over the gulf between the needs and the reality has led to urgent calls for increased access to HCT services [9]. Recent years have witnessed new initiatives to increase access, including incorporating HCT into routine healthcare and providing HCT within people's homes (Home-Based HIV Counseling and Testing or HBHCT). National and international policies have also been revised to incorporate provider-initiated testing and counseling (PITC) [10]. In Uganda options for getting tested are no longer restricted to stand-alone Voluntary Counseling and Testing (VCT) facilities since
C Biomed Central 
HCT services were integrated within broader healthcare and HBHCT was adopted in 2005 [11]. The number of people ever tested for HIV duly increased from $23 \%$ in 2006 ; to $38 \%$ in 2008 , and $57 \%$ in $2010 / 11$ to $57 \%$ in 2010/11 [12-15].

Within HBHCT, providers reach out to the community, providing counseling and testing within clients' homes. In Uganda, HBHCT comes in three different forms. First, some research and surveillance programs include HBHCT as part of their research [14,15]. The second approach is family-based or targeted index client' HCT, mainly used by HIV treatment programs, where the homes of HIV-infected patients registered into care are identified, visited and household members tested for HIV. The third approach, the one used in the area where this study was conducted, is door-to-door HBHCT, where mobile teams of counselors and testers mobilize entire communities and provide HCT door-todoor [11].

HBHCT has been lauded for making testing convenient. It has been commended for its success in increasing uptake, with acceptance rates of over 90\% [16-19]. The high uptake of HBHCT is associated with the elimination of costs for clients traveling to VCT centers and the removal of stigma associated with going to such centers $[16,17,20]$. Menzies and colleagues noted the importance of door-to-door HBHCT for reaching many first-time testers, including couples and children, and for the early identification of HIV infection. They also noted that HBHCT, at US\$ 8.29 per client, is comparatively cheaper than hospital-based HCT (US\$ 11.68) and stand-alone VCT (US\$ 19.26) [17]. Other benefits of HBHCT include the opportunity to reach the entire household with HIV interventions [21].

While there are many advantages to HBHCT, our limited understanding of its processes necessitates further study [22,23]. More specifically, concerns surround: 1) privacy - due to the general lack of counseling space at home [18]; 2) confidentiality - whether health workers can keep clients' results from being revealed to household members and neighbors; 3 ) consent - whether testing at home is really voluntary and whether the right to refuse is not down-played by providers [24]; and 4) whether clients diagnosed with HIV infection are referred and successfully linked to appropriate medical care. Some observers remain cautious about the potential for negative effects in $\mathrm{HBHCT}$, including stigma, discrimination and violence that may come with disclosure of HIV-positive status [25-27]. Similarly, there are concerns about consent and the tension between safeguarding individual rights and protecting public health $[9,28,29]$.

This paper examines the experiences of HBHCT clients in Kumi district in eastern Uganda. We asked clients about: 1) the process of mobilization; 2) counseling, consent, privacy and confidentiality; 3) disclosure and 4) referral to care.

\section{Methods}

This study was conducted as part of the Multi-country African study on Testing and Counseling for HIV (MATCH), designed to compare modes of testing for HIV across four countries: Burkina Faso, Kenya, Malawi and Uganda. The study was conducted in 2008-2009 and included a main survey of clients and providers at healthcare facilities as well as smaller surveys of people involved in home-based testing in Kenya and Uganda, and testing campaigns in Burkina Faso and Malawi. In 2007 and 2008, HBHCT was implemented in selected districts in Kenya and Uganda.

Kumi district $(2,821$ square kilometers) is located in eastern Uganda and has an estimated population of 370,800 (projected from the 2002 census). HIV prevalence in eastern Uganda is estimated at 5.3\% $(\mathrm{MoH}$ and ORC Macro, 2006), while Kumi district authorities have estimated district prevalence to be $3.6 \%$. Kumi has three hospitals (two public and one private) and 27 health centres. A number of these facilities provide HIV-related services, for example Prevention of Mother to Child Transmission (PMTCT). Kumi is the second district in Uganda to provide district-wide door-to-door HBHCT, after Bushenyi [30]. The program was implemented in 2007 by district health services with support from the President's Emergency Plan for AIDS Relief (PEPFAR), through the US Centers for Disease Control and prevention (CDC). HBHCT has been implemented in more than 10 other districts in Uganda, including Bushenyi, Tororo and Kalangala, among others [31].

The district health team trained 29 teams of providers, each with a counselor, a laboratory technician, and mobilizers. The 29 teams moved simultaneously from house to house in the district's 16 sub-counties, providing $\mathrm{HCT}$ services free of charge, using rapid test kits (Determine, Uni-Gold and STAT-PAK) and immediately disclosing results. The teams mobilized a specific number of homes each day, commensurate to their personnel capacity. This meant that they were able to allocate considerable time to conduct comprehensive individual counseling - something that would not be possible in public facilities where providers have additional duties and no control over the number of clients coming to seek services.

Prior to the HBHCT team's visit, community mobilizers ensured that all households were informed of its coming. Mobilizers mainly consisted of local community leaders, though other community resource persons were also trained for this role. Outreach activities were organized in public places such as churches and mosques 
while the district health team held talk shows on the local FM radio stations to mobilize communities for HBHCT. People who were married or cohabiting were encouraged to test as couples rather than individuals. Over $95 \%$ of people who were approached in Kumi district agreed to be tested with a reported prevalence of $4 \%[22]$.

Between April and June 2008, we conducted 395 individual interviews in Kumi district. Kumi was selected because it had recently completed the HBHCT exercise (within six months of this study). This was intended to minimize recall bias.

We adopted the WHO $30 \times 7$ cluster sampling strategy (27). Previously used in studies to estimate coverage levels in the Expanded Program on Immunization (EPI), it employs a simplified cluster sampling method based on the random selection of 210 respondents in 30 clusters (7 respondents per cluster).

In this study, 32 clusters were selected from four (two rural and two urban) sub-counties. For each stratum (rural and urban sub-county), 16 villages (clusters) were randomly selected to provide a total of 32 clusters. Seven households were selected in each village (cluster). In the rural areas where households are scattered, adjacent households were visited. In the urban and peri-urban areas where households are close to each other, we selected every fifth household to avoid selecting all respondents from the same vicinity. In each household, we interviewed up to two eligible respondents. All adults (male and female) in a household (18 years and older) were eligible for participation. The minimum number of respondents would be $224(32 \times 7)$ if only one respondent was interviewed per household. However, the total number of respondents was 395 because we targeted to interview two respondents in every household (except those households where only one person was available at the time of the interview) [32]. Using the rotary method, respondents were randomly selected from those adults present in their homes at the time of the interviews. Overall, $65 \%$ of our respondents were women. Men were probably under-represented in the population that we sampled, because they work more often outside the community (the interviews were done during the day).

We used semi-structured questionnaires to elicit information on the HBHCT processes, from mobilization to counseling, testing, receipt of results and post-test experiences (disclosure and access to services). All respondents provided written informed consent either by signature or thumb print (for those who were unable to write). Participants were asked about the information that they received before testing; whether they consented to or declined to be tested; their perceptions of consent and counseling processes pre- and post-test; disclosure of HIV status and the outcomes of disclosure; and referral to care for those who were found to be HIV-positive.

As our goal was to examine the $\mathrm{HBHCT}$ processes, we excluded those respondents (114) who reported testing before the HBHCT program started in 2007. Clients' experiences were analyzed following the trajectory of HBHCT: from the point of community mobilization to counseling before the test, the consent procedure, posttest counseling and receipt of results, disclosure dynamics and for those found to be HIV-positive, referral to care. We used largely descriptive statistics to document respondents' experiences. The analysis was done by gender to check for gender variations in experiences ( $\mathrm{p}<0.05)$. We also analyzed the open-ended questions that were embedded in our questionnaires using 'cloud analysis' software to identify common themes, which describe client experiences and perceptions across the HBHCT trajectory. Quantitative data were analyzed using the Stata statistical package (2010).

The study was approved the ethics committee of the Amsterdam Medical Center, the Makerere University Child Health and Development Centre, and the Uganda National Council for Science and Technology.

\section{Results}

Out of the 395 individuals interviewed, 376 (95\%) had ever tested for HIV.. Among the 19 who had never tested, six said they had been approached for testing through HBHCT but declined to test. The majority of those who had never tested (12 out of 19) were men. Out of the 376 respondents who had ever tested for HIV, 281 (75\%) had done so through HBHCT in or after 2007. Of this latter group, 12 (4\%) reported being HIVpositive while 262 (96\%) stated that they were not infected; seven declined to declare their HIV status. The experiences of testing at home described below concern the 281 respondents who tested through HBHCT in or after 2007.

Most HBHCT clients (65\%) were married or cohabiting and had little formal education. Cultivation was the leading occupation (51\%), with only $10 \%$ in professional employment and $18 \%$ in trade(see Table 1 ).

In Table 2 the experiences of HBHCT are presented by gender, and in Table 3 the referral experiences are given for the 12 respondents who tested HIV positive.

\section{Mobilization for HBHCT}

The majority (78\%) of respondents received prior information about the visit of the HBHCT team; mobilizers went beforehand to households alerting people about the planned HBHCT exercise; $20 \%$ of the respondents reported that local leaders accompanied the testing team. 
Table 1 Social demographic characteristics of respondents

\begin{tabular}{|c|c|c|c|c|}
\hline \multirow[t]{2}{*}{ Characteristic } & \multicolumn{2}{|c|}{ HBHCT users* } & \multicolumn{2}{|c|}{ HBHCT non-users } \\
\hline & Total $\mathrm{N}=\mathbf{2 8 1}$ & Total \% & Total $\mathrm{N}=19$ & Total \% \\
\hline \multicolumn{5}{|c|}{ Age (1 missing value)t } \\
\hline Under 20 & 26 & $9.3 \%$ & 2 & $10.5 \%$ \\
\hline $20-24$ & 48 & $17.1 \%$ & 2 & $10.5 \%$ \\
\hline $25-29$ & 48 & $17.1 \%$ & 5 & $26.3 \%$ \\
\hline $30-34$ & 50 & $17.8 \%$ & 4 & $21.1 \%$ \\
\hline $35-39$ & 27 & $9.6 \%$ & 3 & $15.8 \%$ \\
\hline $40-44$ & 31 & $11.0 \%$ & 0 & $0 \%$ \\
\hline Over 45 & 50 & $17.8 \%$ & 3 & $15.8 \%$ \\
\hline Missing value & 1 & $0,4 \%$ & & \\
\hline \multicolumn{5}{|l|}{ Gender } \\
\hline Female & 182 & $64.8 \%$ & 7 & $36.8 \%$ \\
\hline Male & 99 & $35.2 \%$ & 12 & $63.2 \%$ \\
\hline
\end{tabular}

\begin{tabular}{lcccc}
\hline Religion & & & & \\
Catholic & 148 & $52.7 \%$ & 13 & $68.4 \%$ \\
Muslim & 9 & $3.2 \%$ & 1 & $5.3 \%$ \\
Pentecostal & 30 & $10.7 \%$ & 1 & $5.3 \%$ \\
$\begin{array}{l}\text { Protestant/ } \\
\text { Church of Uganda }\end{array}$ & 94 & $33.5 \%$ & 4 & $21.1 \%$ \\
\hline
\end{tabular}

\begin{tabular}{|c|c|c|c|c|}
\hline \multicolumn{5}{|l|}{ Education } \\
\hline $\begin{array}{l}\text { No formal education/ } \\
\text { incomplete primary }\end{array}$ & 163 & $58 \%$ & 11 & $57.9 \%$ \\
\hline Primary & 35 & $12,5 \%$ & 0 & $0 \%$ \\
\hline Secondary/vocational & 69 & $2,6 \%$ & 7 & $36,8 \%$ \\
\hline $\begin{array}{l}\text { Post secondary or } \\
\text { higher }\end{array}$ & 9 & $3.2 \%$ & 0 & $0 \%$ \\
\hline Missing value & 5 & $1.8 \%$ & 1 & $5.3 \%$ \\
\hline \multicolumn{5}{|l|}{ Marital status } \\
\hline Never married & 60 & $21.4 \%$ & 8 & $42.1 \%$ \\
\hline Married or cohabiting & 183 & $65.1 \%$ & 9 & $47.4 \%$ \\
\hline Divorced/separated & 15 & $5.3 \%$ & 1 & $5.3 \%$ \\
\hline Widowed & 23 & $8.2 \%$ & 1 & $5.3 \%$ \\
\hline \multicolumn{5}{|l|}{ Type of work** } \\
\hline Agriculture & 142 & $50.5 \%$ & 12 & $63.2 \%$ \\
\hline Homemaker/housewife & 59 & $21.0 \%$ & 2 & $10.5 \%$ \\
\hline Commerce/trade & 51 & $18.1 \%$ & 1 & $5.3 \%$ \\
\hline Student & 24 & $8.5 \%$ & 2 & $10.5 \%$ \\
\hline Professional/employed & 27 & $9.6 \%$ & 1 & $5.3 \%$ \\
\hline Skilled/semi-skilled & 20 & $7.1 \%$ & 2 & $10.5 \%$ \\
\hline Unskilled & 18 & $6.4 \%$ & 2 & $10.5 \%$ \\
\hline Unemployed & 5 & $1.8 \%$ & 2 & $10.5 \%$ \\
\hline Fishing & 1 & $0.4 \%$ & - & - \\
\hline Other & 12 & $4.3 \%$ & - & - \\
\hline
\end{tabular}


Table 2 Experience of HBHCT clients: mobilization, consent, confidentiality and counseling

\begin{tabular}{|c|c|c|c|}
\hline \multirow[t]{2}{*}{ Experience } & \multirow{2}{*}{$\frac{\text { Result total }}{\mathrm{N}=281(\%)}$} & \multicolumn{2}{|c|}{ Results by gender } \\
\hline & & Female $\mathrm{N}=182(\%)$ & Male $\mathrm{N}=99(\%)$ \\
\hline \multicolumn{4}{|l|}{ Mobilization } \\
\hline Informed about the visit of the HBHCT team & 218(77.6) & 147(80.8) & $71(71.7)$ \\
\hline \multicolumn{4}{|l|}{ HBHCT providers: } \\
\hline 1. Came alone & $209(74,4)$ & $136(74.7)$ & $73(73.7)$ \\
\hline 2. Came with local council leaders & $57(20.2)$ & $40(21.9)$ & $17(17.2)$ \\
\hline 3. Came with others & $15(5.5)$ & $6(3.3)$ & $9(9.1)$ \\
\hline \multicolumn{4}{|l|}{ Consent process } \\
\hline Provider asked if client agreed to testing & $271(96.4)$ & $176(96.7)$ & $95(96.0)$ \\
\hline \multicolumn{4}{|l|}{ Respondent considers it important to be asked if he/she agrees } \\
\hline 1. Very important & 245(87.2) & 156(85.7) & $89(89.9)$ \\
\hline 2. Somewhat important & $16(5.7)$ & $14(7.7)$ & $2(2.0)$ \\
\hline 3. Not important & 20(7.1) & 12(6.6) & $8(8.1)$ \\
\hline Provider explained option to decline & $264(94.0)$ & $170(93.4)$ & $94^{1}(94.9)$ \\
\hline Other in the household also offered a test & $171(60,9)$ & $109(59,9)$ & $62(62.6)$ \\
\hline \multicolumn{4}{|l|}{ Response of other household members offered a test } \\
\hline 1. All accepted & $116(67.8)$ & $73(67.0)$ & $43(69.4)$ \\
\hline 2. Some accepted, some refused & $45(26.3)$ & $28(25.7)$ & $17(27.4)$ \\
\hline 3. All refused & $8(4.7)$ & $7(6.4)$ & $1(1.6)$ \\
\hline 4. Don't know & $2(1.2)$ & $1(0.9)$ & $1(1.6)$ \\
\hline Discussed test with other household members before consenting & $90(52,9)$ & $57(52,8)$ & $33(53,2)$ \\
\hline Influenced by what other household members said or did & $36(40.0)$ & $24(42.1)$ & $12^{2}(36.4)$ \\
\hline \multicolumn{4}{|l|}{ Counseling } \\
\hline Received counseling before the test & $254(90.4)$ & $163(89.6)$ & $91(91.9)$ \\
\hline Tested alone/individual & $188(74.0)$ & $129(79.1)$ & $59(64.8)$ \\
\hline \multicolumn{4}{|l|}{ Where pre-test counseling was done: } \\
\hline 1. Inside house & $120(48.0)$ & $73(45.9)$ & $47(51.6)$ \\
\hline 2. Outside & $129(51.6)$ & $86(54.1)$ & $43(47.3)$ \\
\hline Provider explained how test works, pre-test & $207(81.5)$ & $128(78.5)$ & $79^{3}(86.8)$ \\
\hline Provider explained meaning of positive and negative results, pre-test & $236(84.0)$ & $153(84.1)$ & $83^{4}(83.8)$ \\
\hline Provider explained meaning of test result, post-test & $272(98.2)$ & $174(97.2)$ & $98(100.0)$ \\
\hline Provider explained window period post-test & $221(87.7)$ & $140(86.4)$ & $81(90)$ \\
\hline Provider gave opportunity to ask questions, post-test & $234(93.2)$ & $148(92.5)$ & $86(94.5)$ \\
\hline Provider gave advice on prevention of HIV, post-test & $264(95.3)$ & $169(94.4)$ & $95(96.9)$ \\
\hline \multicolumn{4}{|l|}{ Confidentiality } \\
\hline Client told that results will remain confidential & $246(97.6)$ & $159(98.1)$ & $87(96.7)$ \\
\hline \multicolumn{4}{|l|}{ How the client valued confidentiality } \\
\hline 1. Very important & $218(78.7)$ & $141(78.8)$ & $77(78.6)$ \\
\hline 2. Somewhat important & $17(6.1)$ & $13(7.3)$ & $4(4.1)$ \\
\hline 3. Not important & $41(14.8)$ & $24(13.4)$ & $17(17.3)$ \\
\hline \multicolumn{4}{|l|}{ Client felt results were kept confidential } \\
\hline 1. Yes & $196(70.8)$ & $126(70.4)$ & $70(71.4)$ \\
\hline 2. No & $9(3.2)$ & $7(3.9)$ & $2(2.0)$ \\
\hline 3. Don't know & $71(25.6)$ & $45(25.1)$ & $26(26.5)$ \\
\hline
\end{tabular}


Table 2 Experience of HBHCT clients: mobilization, consent, confidentiality and counseling (Continued)

\begin{tabular}{|c|c|c|c|}
\hline \multicolumn{4}{|l|}{ Disclosure } \\
\hline Provider suggested sharing results with someone & 149 (53.8) & $99(55.3)$ & $50(51.0)$ \\
\hline Other people in the household shared results with respondent & $125(45.1)$ & $76^{5}(42.5)$ & $49(50.0)$ \\
\hline Asked by household member to share results & $79(28.5)$ & $48^{6}(26.8)$ & $31(31.6)$ \\
\hline Neighbors asked if respondent took an HIV test & $136(49.1)$ & $86^{7}(48.0)$ & $50(51.0)$ \\
\hline Neighbors asked to share HIV test results & $76(27.4)$ & $49^{8}(27.4)$ & $27(27.6)$ \\
\hline Generally keep results confidential & $186(66.2)$ & $126^{9}(69.2)$ & $60^{10}(60.6)$ \\
\hline Has disclosed to someone & $219(77.9)$ & $144^{11}(79.1)$ & $75^{12}(75.8)$ \\
\hline \multicolumn{4}{|l|}{ People disclosed to (multiple responses) } \\
\hline Spouse/partner & $135(61.6)$ & $90(62.5)$ & $45(60.0)$ \\
\hline Parents & $68(31.1)$ & $46(31.9)$ & $22(29.3)$ \\
\hline Children & $42(19.2)$ & $27(18.8)$ & $15(20.0)$ \\
\hline Siblings & $32(14.6)$ & $22(15.3)$ & $10(13.3)$ \\
\hline Other relatives & $57(26.0)$ & $30(20.8)$ & $27(36.0)$ \\
\hline Friends* & $99(45.2)$ & $55(38.2)$ & $44(58.7)$ \\
\hline Client has discussed HIV status with someone in household* & $155(56.0)$ & $92^{13}(51.4)$ & $63(64.3)$ \\
\hline \multicolumn{4}{|l|}{ Satisfaction } \\
\hline Received sufficient information & $259(93.5)$ & $165(92.2)$ & $94(95.9)$ \\
\hline Meeting with provider was helpful & $262(94.6)$ & $167(93.3)$ & $95(96.9)$ \\
\hline \multicolumn{4}{|l|}{ Overall treatment by provider } \\
\hline Very well & $168(60.6)$ & $106(59.2)$ & $62(63.3)$ \\
\hline Well & $52(18.8)$ & $34(19.0)$ & 18 (18.4) \\
\hline Okay & $53(19.1)$ & 35 (19.6) & $18(18.4)$ \\
\hline Badly & $4(1.4)$ & $4(2.2)$ & $0(0.0)$ \\
\hline
\end{tabular}

*significant $\mathrm{p}$.

1. 1 missing value.

2. 1 missing value.

3. 1 missing value.

4. 1 missing value.

5. 3 missing values.

6. 2 missing values.

7. 1 missing value.

8. 1 missing value.

9. 3 missing values.

10. 2 missing values.

11. 3 missing values.

12. 2 missing values.

13. 1 missing value.

\section{Pre- and post-test counseling}

Most respondents (90\%) stated that they were counseled before the test, and $94 \%$ of clients felt that the information they received from providers was sufficient and useful.

Of those who received pre-test counseling, the majority (74\%) received one-on-one counseling. However, we found high rates of couple counseling among the married/co-habiting respondents ( $\mathrm{N}=49)$ : $69 \%$ were counseled and tested with their partner. Regarding the physical location where the counseling took place, $52 \%$ reported that it was done outside the house, while $48 \%$ reported that they were counseled inside the house.
The quality of counseling was high (see Table 2); 95\% of the respondents reported that they received information on prevention in post-test counseling. The majority (93\%) stated that they were allowed to ask questions during the post-test counseling session. Respondents were satisfied with the interactions. Most respondents (94\%) said the information they received was sufficient; 95\% thought the meeting with the provider was helpful.

\section{Confidentiality}

Almost all respondents (98\%) stated that they had been assured by the HBHCT team that their results would remain confidential. When asked about the importance of confidentiality, $78 \%$ said it was very important, while $6 \%$ 
Table 3 Referral to care and support for those tested positive

\begin{tabular}{lr}
\hline Referral service & Number (\%) $\mathbf{N = 1 2}$ \\
\hline Told medication was needed & $11(91.7)$ \\
Given further medical/blood tests & $9(75.0)$ \\
Does client know CD4 count & $5(55.6)$ \\
Referred to medical care & $8(66.7)$ \\
Has obtained medical care & $7(87.5)$ \\
Advised to join HIV \& AIDS support group & $11(91.7)$ \\
Referred to a PHA support group & $11(91.7)$ \\
Has joined support group & $8(66.7)$ \\
Received assistance (e.g. food) & $3(25.0)$ \\
\hline
\end{tabular}

said it was somewhat important, and $15 \%$ said it was not important.

One respondent described HBHCT as " $a$ wonderful practice that allows a lot of privacy." Most respondents reported that HBHCT allowed confidentiality and freedom of discussion between clients and providers: "I think it is good because when people are reached individually in their own homes they can open up easily."

Some respondents stated that HCT in the privacy of their own homes allows for greater confidentiality than testing in health facilities, where there are many other people: "It's very good [testing at home] because some people fear going to hospital, the reason being that if they are found positive other people will know about their status."

Regarding the protection of test results by providers, the majority of respondents $(71 \%)$ felt that their results were protected, including 10 out of the 12 who reported testing HIV-positive; only $3 \%$ reported that they felt their results were not kept confidential.

\section{Disclosure dynamics}

Overall, $49 \%$ of HBHCT clients reported that neighbors had asked them if they had been tested, and $28 \%$ had been asked to share their HIV test results; $29 \%$ reported that their household members had asked them to share their results. There were no significant differences between men and women's experiences in this regard. An almost equal proportion of women (79\%) and men (76\%) reported that they had disclosed to someone; of those who had disclosed $63 \%$ of women and $60 \%$ of men did so to their spouse/partners. A larger proportion of men than women reported that they had discussed their HIV status with other members of the household (64\% versus $51 \%, \mathrm{p}=0.058)$. Similarly, a larger proportion of men $(59 \%)$ than women (38\%) had disclosed to their friends $(p=0.006)$. Slightly more women than men reported that they generally keep their status confidential $(69 \%$ versus $61 \%)$.

Among the 12 respondents who reported to be HIVpositive, all had disclosed to someone. All HIV positive individuals who were married or cohabiting had disclosed to their partners (one via their mother-in-law). Participants acknowledged disclosure and asking a partner to test as a difficult process and gave varied experiences.. One HIV infected young man, for example, said he had spoken to his wife about having a test:

"I told her that we should go and get tested so that if we are HIV positive we start treatment...I was sure I did not have HIV because I tried being faithful to my partner". He says he disclosed to his wife because "she had a right to know my status". At first she was distressed and wished that they hadn't gone for testing, but "now we have accepted our status", he says.

One HIV infected woman reported that she was alone in the house during home-based testing. When she found out that she was positive she disclosed to her husband, as "there is no way I was going to hide this". Describing how he reacted, she says he was rude and did not want anything to do with testing or taking drugs. He wanted to break-up. But she said: "lately he has changed and now he is supportive".

Another HIV infected woman narrated how her mother in-law asked her what her test result was. "I told her what the counselor had told me". She said that her co-wife subsequently asked whether it was true. She decided to tell her, and was relieved that her co-wife "did not react badly", but instead supported her and encouraged her to start treatment.

Half of those who tested HIV-positive did not think it was important.

\section{Referral to care}

Eleven out of 12 clients who tested HIV positive said they needed medication but only eight said that they had been referred to medical care by the HBHCT providers and seven had received care. When probed about their health status, five said they knew their CD4 counts. Eleven HIV-positive respondents were counseled to join support groups and 8 of them had done so.

While most respondents valued the privacy of their homes for testing, several of the HIV positive respondents felt that testing at a health facility had advantages over testing at home:

"When you are at the health centre you easily find out about other health problems rather than [testing for] HIV alone." One HIV positive respondent remained skeptical about HIV testing at home, noting that: "It's a 
good idea but I am not sure if their results are as genuine as the hospital results."

In general, our respondents stated that HBHCT had enabled those who were infected to initiate treatment after learning of their HIV status as one of them commented:

"It is good, even my sick auntie who could not go to hospital was tested and found positive; now she is on medication." "It is very good, even people who were bedridden got tested and now they are on treatment; they are even better than they were before they knew they were positive."

\section{Discussion}

This study revealed high levels of uptake of HIV testing and counseling and overall satisfaction with HBHCT. The percentage of respondents who had ever tested was much higher than the national average of $38 \%$ at the time [13]. All individuals who tested received their results immediately, facilitated by the use of rapid test kits. Similar results have been reported by other HBHCT studies andprograms [16-18,30,33], suggesting that if expanded, HBHCT could increase uptake of HIV testing and reach many first-time testers.

The quality of services and the attitude of healthcare providers are often cited as limiting factors in the use of HIV counseling and testing services [31,34]. In our study, both male and female clients reported largely positive experiences with HBHCT: the information they received during pre- and post-test counseling, the consent procedure, and general handling by providers. Most respondents were counseled before the test and felt that the information they received from providers was sufficient. Allowing clients to ask questions was highly valued.

We found high adherence to consent requirements on the part of the HBHCT providers, in particular explanation of the opt-out option. Nearly all (94\%) respondents (both male and female) acknowledged being given the chance to opt out of the test; and they valued this. The Kumi HBHCT teams were able to allocate considerable time to conduct comprehensive individual counseling since they controlled the number of households and individuals served on each day.

Contrary to our expectation that privacy within homes would be problematic due to limited space and the presence of other family members, clients considered their own homes as more private than healthcare facilities. Most respondents were satisfied with the privacy offered by HBHCT. Other studies have described the involvement of families in seeking private counseling space within and outside the home [20]. The participation of clients in identifying private spaces within the home was experienced as empowering, in contrast to facilities where users have no say over the setting of testing and counseling.

While most clients were satisfied with the level of privacy, more than a quarter cast doubt on whether their test results would be safeguarded after providers left their homes. In this study, no direct question was asked about breach of confidentiality by the provider. Nonetheless, in order to build trust and confidence, HBHCT clients should be informed about the practical issues of confidentiality beyond the test process and what happens to records when providers leave their homes.

It is widely assumed that individuals do not want others to know that they have tested for HIV [35]. In the context of HBHCT, anonymity may be impossible. Family members and neighbors knew about the visiting HBHCT team and tried to find out whether others had taken the test. Almost half of the respondents were asked by other community members if they had taken the HIV test. Nevertheless, we found that anonymity was not a major concern among respondents as there was no stigma attached to testing: most household and community members were in the same boat. Those who declined to test were the minority. This is unlike testing in a voluntary testing and counseling facility where lone individuals who go for testing prefer to hide their identity [36]. HBHCT opened up space within the home to talk about HIV and testing. To some extent, interactions and discussions among partners and other family members influenced individual decisions to test at home, though others stated, that testing was a personal responsibility. The dynamics of these discussions varied between respondents; patterns of influence often did not conform to the traditional hierarchy of many African families (e.g. parents over children, husbands over wives). For example, we found sons and daughters to have encouraged their parents to take the test.

Prior mobilization allows potential clients to think about, discuss and make a decision before the team arrives. This is similar to VCT where an individual can take time to consider whether or not to be tested. Individuals who do not wish to be tested could, for example, leave home before the arrival of the HBHCT team. The involvement of local leaders in the mobilization process can influence individual decisions to take the test; their involvement encouraged trust in the program and community cooperation. Although not a focus of this study, the widespread mobilization and discussions around HIV within the homes and community may change the norms around HIV testing and impact on HIV stigma, discrimination and access to services.

Disclosure levels were found to be high: $78 \%$ of HBHCT clients had disclosed their HIV test results to 
someone, often to more than one person. However, the disclosure was selective as reported in other studies $[37,38]$. Men were found to disclose significantly more to others in the household and to friends than women. This is an interesting finding, as other studies suggest that men are more secretive about their status than women. It is important to note here that $96 \%$ of our informants were negative. For those who test negative, disclosing is perhaps not a big deal. Disclosure problems are more likely to occur for those who test positive. However, some previous studies have demonstrated no increases in domestic violence or other negative social outcomes after HBHCT [39]. Our findings show that all of the HIV positive respondents had disclosed their results to someone. Many clients tested (69\%) were counseled with their partners, suggesting that homebased testing is a good way to promote couple-counseling. Couple counseling and testing may also explain the high disclosure rates to sexual partners, in comparison to other studies $[30,40]$.

The findings from this study may have some limitations: 1) Recall bias (some respondents had tested more than a year prior to the interview); 2) This study gathered information on only individuals who were present at home at the time of the interview, which may exclude the views of those who were out (at work); 3) The study generally relied on respondent accounts which may be subject to bias due to social desirability. However, in real life, it is users' perceptions that trigger many health actions including care, and it is thus important to explore the client perspectives.

The number of HIV infected individuals was too small to exhaustively explore linkage to and access to HIV care and treatment as well as outcomes of HIV status disclosure among the HIV infected individuals. However, most of the HIV infected respondents confirmed referral to medical care and support groups, similar to another study of HBHCT in western Uganda [30]. Even with the linkage to care challenges, HBHCT can still play a major role since several studies demonstrate that knowing one's status if a person is HIV-infected, has a substantial benefit in terms of risk reduction $[41,42]$.

Several studies show that HBHCT increases uptake of HIV testing, identifies infected individuals earlier, and reaches more couples and children, in comparison to other HCT approaches $[21,30]$. Despite the ethical concerns, our study shows good adherence to standard HIV counseling and testing recommendations (consent, counseling, confidentiality and referral to care) and appreciation of the $\mathrm{HBHCT}$ approach by the community.

\section{Conclusion}

This study also shows high coverage of HIV testing within the Kumi district community after HBHCT, with many individuals testing as couples. HBHCT can play a significant role in rapidly increasing access to HIV testing, care and treatment as well as prevention services.

\section{Competing interests}

The authors declare that they have no competing interests.

\section{Authors' contributions}

DK initiated the topic and wrote the first draft of the paper. RW and $\mathrm{AH}$ contributed to the design of the topic, interpretation of findings and writing of the paper. JK contributed to the interpretation and writing of the paper. All authors read and approved the final manuscript.

\section{Acknowledgments}

This project was supported by a grant from the National Institutes of Health (5 R01 HD053268-05, PI: Carla Obermeyer). This support is gratefully acknowledged. We acknowledge the contribution of the management of Makerere University Child Health and Development Centre and Mr. Richard Sekiwunga. We thank David Hymans for his editorial support, which improved the stucture of the article substantially.

\section{Author details}

${ }^{1}$ Department of Social Work/Child Health and Development Centre, Makerere University, Kampala, Uganda. ${ }^{2}$ Department of Disease Control and Environmental Health, Makerere University School of Public Health, Kampala, Uganda. ${ }^{3}$ Department of Public Health and Clinical Medicine, Umeå Centre for Global Health Research, Epidemiology and Global Health Unit, Umeå University, 901 85, Umeå, Sweden. ${ }^{4}$ Centre for Social Science and Global Health, University of Amsterdam, Amsterdam, Netherlands.

Received: 7 August 2012 Accepted: 29 October 2012

Published: 12 November 2012

\section{References}

1. Leach-Lemens C, Owuor J: Scaling up HIV testing and counselling towards universal access: What works in resource-limited settings? HATIP 2009, 146:2-10.

2. Granich RM, Gilks CF, Dye C, De Cock KM, Williams BG: Universal voluntary HIV testing with immediate antiretroviral therapy as a strategy for elimination of HIV transmission: a mathematical model. Lancet 2009, 373(9657):48-57

3. Montaner JSG, Lima VD, Barrios R, Yip B, Wood E, et al: Association of highly active antiretroviral therapy coverage, population viral load, and yearly new HIV diagnoses in British Columbia, Canada: a populationbased study. Lancet 2010, 376(9740):532-539.

4. Donnell D, Baeten JM, Kiarie J, Thomas KK, Stevens W, For the Partners in Prevention HSV/HIV Transmission Study Team, et al: Heterosexual HIV-1 transmission after initiation of antiretroviral therapy: a prospective cohort analysis. Lancet 2010, 375((9731):2092-2098.

5. WHO/UNAIDS/UNICEF: Towards universal access: Scaling up priority HIV/AIDS interventions in the health sector. Progress report. Geneva: World Health Organization; 2010

6. De Cock KM, Marum E, Mbori-Ngacha D: A serostatus approach to HIV/ AIDS prevention and care in Africa. Lancet 2003, 362:1847-1849.

7. UNAIDS: Report on the global AIDS epidemic. Geneva: UNAIDS; 2010.

8. Bunnell R, Cherutich P: Universal HIV testing and counseling in Africa. Lancet 2008, 371:2148-2150.

9. Obermeyer CM, Osborn M: The utilization of testing and counseling for HIV: A review of the social and behavioral evidence. Am J Pub Health 2007, 10:1762-1774.

10. WHO: Guidelines on provider-initiated HIV counselling and testing in health facilities. Geneva: WHO; 2007.

11. Ministry of Health: Uganda national policy guidelines for HIV voluntary counselling and testing. Kampala: $\mathrm{MOH} ; 2005$.

12. Uganda Bureau of Statistics (UBOS) and Macro International Inc: Uganda demographic and health survey 2006. Calverton: UBOS and Macro International Inc; 2007

13. Ministry of Health, Republic of Uganda: Performance report: STD/AIDS Control Program 2007/2008. Kampala: MOH; 2008. 
14. Ministry of Health [Uganda] and ORC Macro: Uganda HIV/AIDS serobehavioural survey 2004-2005. Calverton: Ministry of Health and ORC Macro; 2006.

15. Ministry of Health [Uganda] and ICF International Calverton Maryland, USA Uganda AIDS Indicator Survey. Kampala: MOH; 2011.

16. Wolff B, Nyanzi B, Katongole $H$, et al: Evaluation of a home-based voluntary counseling and testing intervention in rural Uganda. Health Policy Plan 2005, 20:109-116.

17. Were W, Mermin J, Bunnell R, Ekwaru JP, Kaharuza F: Home-based model for HIV voluntary counselling and testing. Lancet 2003, 361:1569.

18. Matovu JK, Kigozi G, Nalugoda F, Wabwire-Mangen F, Gray RH: The Rakai Project counselling programme experience. Trop Med Int Health 2002, 7:1064-1067.

19. Helleringer S, Kohler HP, Frimpong JA, Mkandawire JRN: Increasing uptake of HIV testing and counseling among the poorest in Sub-Saharan countries through home-based service provision. J Acquir Immune Defic Syndr 2009, 51:185-193.

20. Yoder PS, Katahoire AR, Kyaddondo D, Akol Z, Bunnell R, Zaharuza F: Homebased HIV testing and counselling in a survey context in Uganda. Calverton: ORC Macro; 2006.

21. Menzies N, Abang B, Wanyenze R, et al: The costs and effectiveness of four HIV counseling and testing strategies in Uganda. AIDS 2009, 23:395-401.

22. Nabalonzi JK, et al: Home based HIV counseling and testing promotes HIV status disclosure, partner testing and adherence to therapy. AIDS.: XVI International AIDS Conference; 2006. Abstract no. WEPE0556.

23. Bateganya M, Abdulwadud OA, Kiene SM: Home-based HIV voluntary counselling and testing (VCT) for improving uptake of HIV testing. Cochrane Database of Systematic Reviews 2010, 7. doi:10.1002/14651858. CD006493.pub4. Art. No.: CD006493.

24. Mutale W, Michelo C, Jürgensen M, Fylkesnes K: Home-based voluntary HIV counselling and testing found highly acceptable and to reduce inequalities. BMC Publ Health 2010, 10:347.

25. Mills EJ, Chong S: Lesotho embarks on universal HIV testing. HIV AIDS Policy Law Rev 2006, 1:27-8.

26. Csete J, Schliefer R, Cohen J: "Opt-out" testing for HIV in Africa: A caution. Lancet 2004, 363:493-4.

27. Kippax S: A public health dilemma: A testing question. AIDS Care 2006, 3:230-5.

28. Maher JE, Peterson J, Hastings $\mathrm{K}$, et al: Partner notification and women's decision to have an HIV test. J Acquir Immune Defic Syndro 2000, 25:276-282.

29. April MD: Rethinking HIV, exceptionalism: The ethics of opt-out HIV testing in sub-Saharan Africa. Bull World Health Organ 2010, 88:703-708.

30. Tumwesigye E, Wana G, Kasasa S, Muganzi E, Nuwaha F: High uptake of home-based, district-wide, HIV counseling and testing in Uganda. AIDS Patient Care STDs 2010, 11:735-741.

31. Uganda AIDS Commission: Report on Implementation of National HIV and AIDS Strategic Plan - FY 2007/2008. Republic of Uganda: Kampal: Uganda AIDS Commission; 2008.

32. Hoshaw-Woodard S: Description and comparison of the methods of cluster sampling and lot quality assurance sampling to assess immunization coverage. Geneva: World Health Organization, Vaccine Assessment and Monitoring Team of the Department of Vaccines and Biologicals; 2001. www.who.int/vaccines-documents.

33. Angotti N, Bula A, Gaydosh L, Kimchi EZ, Thornton RL, Yeatman SE: Increasing the acceptability of HIV counseling and testing with three C's: Convenience, confidentiality and credibility. Soc Sci Med 2009, 68:2263-2270

34. Nuwaha F, Kabatesi D, Muganwa M, Whalen CC: Factors influencing acceptability of voluntary counseling and testing in Bushenyi district. East Africa Med J 2002, 79:626-632.

35. Marum E: Innovations, issues and debates in HIV testing and counselling. Windhoek, Namibia: HIV/AIDS Implementers Conference; 2009.

36. Whyte SR, Whyte M, Kyaddondo D: Health workers entangled: Confidentiality and certification. In Morality, Hope and Grief: Anthropologies of AIDS in Africa. Edited by Dilger H, Luig U. Oxford: Berhahn Books; 2010:80-101.
37. Mogensen $\mathrm{H}$ : New hopes and new dilemmas: Disclosure and recognition in the time of anti retro viral treatment. In Morality, Hope and Grief: Anthropologies of AIDS in Africa. Edited by Dilger H, Luig U. Oxford: Berhahn Books; 2010:61-79.

38. Ssali S, Atuyambe L, Tumwine C, et al: Reasons for disclosure of HIV status by people living with HIV/AIDS and in HIV care in Uganda: An exploratory study. AIDS Patient Care STDs 2010, 10:675-681.

39. Apondi $R$, et al: Home-based antiretroviral care is associated with positive social outcomes in a prospective cohort in Uganda. JAIDS 2007, 44:71-6.

40. Bunnell R, Opio A, Musinguzi J, et al: HIV transmission risk behavior among HIV-infected adults in Uganda: results of a nationally representative survey. AIDS 2008, 22:617-24.

41. Marks G, Crepaz N, Janssen RS: Estimating sexual transmission of HIV from persons aware and unaware that they are infected with the virus in the USA. AIDS 2006, 20(10):1447-50.

42. Marks G, Crepaz N, Senterfitt JW, Janssen RS: Meta-analysis of high-risk sexual behavior in persons aware and unaware they are infected with HIV in the United States: implications for HIV prevention programs. J Acquired Immune Deficiency Syndrome 2005, 39(4):446-53.

doi:10.1186/1471-2458-12-966

Cite this article as: Kyaddondo et al.: Home-based HIV counseling and testing: Client experiences and perceptions in Eastern Uganda. BMC Public Health 2012 12:966.

\section{Submit your next manuscript to BioMed Central and take full advantage of:}

- Convenient online submission

- Thorough peer review

- No space constraints or color figure charges

- Immediate publication on acceptance

- Inclusion in PubMed, CAS, Scopus and Google Scholar

- Research which is freely available for redistribution

Submit your manuscript at www.biomedcentral.com/submit
C) BioMed Central 